\title{
Penanggulangan Gelandangan Pada Jabatan Kebajikan Negeri Kedah Malaysia Melalui Layanan Konseling Islam
}

\author{
Nurul Husna Binti Abd Malek', M. Fahli Zatrahadi ${ }^{2}$ \\ 1,2 Uin Sultan Syarif Kasim Riau \\ Email: nurulhusnamalek@gmail.com
}

\begin{abstract}
Abstrak
Penelitian ini bertujuan mendeskripsikan teknik Konseling Islam yang dilakukan oleh petugas Konselor dalam kegiatan konseling yang dilakukan konselor dari JKMNK kepada gelandangan yang ada di kota alor setar. Penelitian ini adalah penelitian kualitatif, yaitu penelitian berjenis penelitian lapangan field research. Dari hasil penelitian ini proses konseling Islam yang ada di JKM menggunakan tiga tahap yaitu tahap awal, tahap pertengahan, tahap akhir, gelandangan dapat mengikuti tahap - tahap konseling dengan baik sehingga gelandangan dapat teguh keimananya, secara khususnya kesehatan jiwa dan mental, dapat mengendalikan diri dan memahami apa yang diperintahkan dan dilarang oleh Allah SWT sehingga apabila gelandangan sudah keluar kepada masyarakat luar mereka tidak lagi merasakan rendah diri dan juga dapat menyesuaikan diri di lingkungan.
\end{abstract}

\section{Kata Kunci: Bimbingan Konseling Islam, Menanggulangi Gelandangan}

\begin{abstract}
This study aims to describe the Islamic counseling techniques performed by counselor officers in counseling activities conducted by counselors from JKMNK to homeless people in the city of Alor Setar. This research is a qualitative research, which is a type of field research. This research uses data collection techniques, interviews, observations, and documentation. The data sources of this research are primary data and secondary data. From the results of this study, the Islamic counseling process in JKM uses three stages, namely the initial stage, the middle stage, the final stage, the homeless person can follow the counseling stages well so that the homeless can be firm in his faith, especially mental and mental health, can control themselves and understand what Allah SWT commands and prohibits so that when the homeless person comes out to the outside community they no longer feel inferior and can also adjust to the environment.
\end{abstract}

\section{Keyword: Islamic Counseling, Guidance, Handling Homeless People}

\section{Pendahuluan}

Gelandangan dan pengemis memang telah menjadi masalah nasional yang dihadapi di banyak kota, tidak terkecuali di Negara maju (Rohman, 2011). Permasalahan gelandangan dan pengemis sebenarnya telah lama mendapatkan perhatian serius baik dari pemerintah pusat dan pemerintah daerah bahkan secara ekstrim mengibaratkan gelandangan sebagai penyakit kanker yang diderita kota karena keberadaannya yang mengganggu keindahan dan kenyamanan kota, namun begitu susah dan komplek dalam penanggulangannya (Rohman, 2011).

Fenomena gelandangan kini dilihat semakin meluas terutamanya di kota-kota besar seluruh dunia. Di Malaysia, khusunya Kuala lumpur yang menjadi ibu Negara serta tupuan masyarakat sama ada dari dalam dan luar negeri memperlihatkan angka gelandangan yang dikeluarkan oleh Jabatan Kebajikan Masyarakat adalah seramai 1,387 orang. Manakala sekitar tahun 2011 dan tahun 2012, jumlahnya dijangka meningkat oleh pihak Yayasan Kebajikan Negara berikutan taburan golongan gelandangan yang dapat dilihat sekitar ibu kota (Mohamed, 2015). 
Menurut kajian yang dikeluarkan oleh "Economist Intelligence Unit" (EIU) di bawah majalah The Economist dalam (Nazif Mohd, 2013)mendapati biaya kehidupan yang ada di Malaysia meningkat hampir $25 \%$ pada tahun 2011 dan yang terbaru adalah peningkatan harga barang seperti gula dan minyak menyebabkan meningkatnya bilangan gelandangan di Negara ini, hal ini akan mengakibatkan mereka terpaksa menanggung biaya hidup yang semakin tinggi.

Merujuk kepada pengertiannya, gelandangan adalah orang-orang yang hidup tidak layak kondisinya bertentangan dengan aturan masyarakat setempat, serta tidak mempunyai tempat tinggal dan pekerjaan tetap dan kehidupannya berpindah-pindah dari satu ke tempat yang lain. Sedangkan pengemis adalah orang-orang yang mendapatkan uang dengan meminta-minta di muka umum dengan berbagai cara dan alasan agar mendapatkan belas kasihan dari orang lain (Fitri, 2019).

Dalam keterbatasan ruang lingkup sebagai gelandangan tersebut, mereka berjuang untuk mempertahankan hidup di daerah perkotaan dengan berbagai macan strategi, seperti menjadi pemulung, pengemis, pengamen, dan pengasong. Perjuangan hidup sehari-hari mereka mengandung resiko yang cukup berat, tidak hanya karna tekanan ekonomi, tetapi juga tekan sosial budaya dari masyarakat, kerasnya kehidupan jalanan, dan tekanan dari aparat ataupun petugas ketertiban kota (Twikromo, 1999).

Gelandangan dan pengemis sering kali menjadi suatu kumpulan yang tak terpisahkan, dengan kehidupan jalanan. Utamanya jalanan kota besar selalu identic dengan ketiga hal tersebut, yang secara legal adalah perbuatan yang melanggar norma dan hukum, namun disisi lain konstitusi mengamanahkan kesejahteraan menjadi tanggung jawab Negara, ketika menjadi fenomena tersebut maka mengindikasi tanggung jawab Negara dalam hal kesejahteraan sebagai sumber permasalahan masih dipertanyakan, dan banyak lainnya factor penyebab fenomena munculnya gelandangan dan pengemis, beberapa sumber baik buku maupun jurnal serta penelitian terdahulu menberikan penjelasan factor penyebab yang berbeda-beda namun memiliki kecenderungan kesamaan (Nusanto, 2017).

Salah satu penyebab mengapa gelandangan di permasalahkan yaitu karena kebanyakan para gelandangan itu tinggal di pemukiman kumuh dan liar, menempati zona-zona publik yang sebenarnya melanggar hukum, dengan cara mengontak petak-petak di daerah kumuh di pusat kota atau mendiami stren-stren kali sebagai pemukim liar (Zefianningsih, Wibhawa, \& Rachim, 2016). Artijo Alkostar dalam (Ahmad, 2010)Dari beberapa hasil pengamatan terhadap gelandangan, dapat disebutkan bahawa penyebab munculnya gelandangan di kota-kota besar dibedakan kedalam faktor intern dan faktor ekstern. Faktor intern meliputi; faktor malas, tidak mau kerja, mental tidak kuat, adanya cacat fisik dan adanya cacat psikis (jiwa). Sedangkan faktor ekstern terdiri dari; faktor ekonomi, geografi, sosial, pendidikan, psikologis, kultural, lingkungan dan agama(Miftahuddin, Zatrahadi, Suhaimi, \& Darmawati, 2019).

Hal inilah yang menjadi penyabab keengganan gelandangan untuk kembali ke daerahnya selain karena perasaan malu karena berpikir bahwa daerahnya memilliki lapangan kerja yang lebih sempit daripada tempat dimana mereka tinggal sekarang. Mereka memutuskan untuk tetap meminta-minta, mengamen, memulung dan berjualan seadanya hingga pekerjaan yang lebih baik menjemput mereka. Selain itu, masalah yang hingga saat ini belum teratasi yaitu kemiskinan yang sangat mempengaruhi munculnya gelandangan pada lansia. Permasalahan yang sangat dirasakan oleh kaum miskin yaitu permasalahan sosial ekonomi mereka, yakni karena mereka tidak mempunyai ekonomi yang cukup, maka mereka tidak bisa membeli rumah sehingga mereka memutuskan untuk menjadi gelandangan (Muslim, 2013).

Untuk mencapai tujuan yang maksimal dalam pelaksanaan Bimbingan Konseling Islam, maka diperlukan suatu organisasi yang baik. Organisasi dalam pengertian umum adalah suatu 
badan yang mengatur segala kegiatan untuk mencapai tujuan. Bimbingan dan konseling tidak dapat dilaksanakan dengan baik tanpa ada organisasi dan administrasi yang baik dan sempurna. Tanpa adanya organisasi, maka tidak terdapat koordinasi, perencanaan, sasaran yang jelas, pengawasan dan kepimpinan yang berwibawa, tegas dan bijaksana. Dengan arti lain, suatu organisasi yang baik ditandai oleh adanya dasar dan tujuan organisasi dan perencanaan yang matang.

Menurut (Amin, 2010), Bimbingan adalah bantuan yang diberikan kepada seseorang secara sistematis untuk mengembangkan potensi yang dimilikinya dalam upaya mengatasi berbagai persoalan sehingga ia dapat menetukan sendiri jalan hidupnya secara bertanggungjawab.

Bimbingan dan konseling Islami menurut (Gudnanto, 2015) upaya membantu individu belajar mengembangkan fitrah-iman dan atau kembali kepada fitrah-iman, dengan cara memberdayakan (enpowering) fitrah-fitrah (jasmani, rohani, nafs, dan iman) mempelajari dan melaksanakan tuntunan Allah dan rasul-Nya, agar fitrah-fitrah yang ada pada individu berkembang dan berfungsi dengan baik dan benar. Pada akhirnya diharapkan agar individu selamat dan memperoleh kebahagiaan yang sejati di dunia dan akhirat. Seperti yang dikemukakan oleh Gladding dalam (Sam Hisam, 2014) yang berpendapat bahawa pembedaan istilah bimbingan (guidance) dan konseling adalah bahwa bimbingan berfokus kepada membantu individu membuat pilihan hidup yang penting sedangkan konseling berfokus pada membantu individu untuk berubah.

Menurut (Bakran Adz-Dzaky, 2002)Bimbingan Konseling Islam adalah suatu aktivitas pemberian nasehat dengan berupa anjuran-anjuran dan saran-saran dalam bentuk pemberian yang komunikatif antara konselor dan konseli atau klien, yang mana konseling datang dari pihak klien yang disebabkan karena ketidaktahuan atau kurangnya pengetahuan sehingga ia memohon pertolongan kepada konselor.

Jabatan Kebajikan Masyarakat (JKM) telah ditubuhkan pada bulan April 1946. Di dalam jangkamasa 72 tahun, Jabatan Kebajikan Masyarakat telah mengalami evolusi dalam memenuhi peranannya di dalam pembangunan negara. Bermula dengan penglibatan menangani pelbagai masalah yang timbul akibat Perang Dunia Kedua, peranan dan fungsi Jabatan ini telah berkembang kepada perkhidmatan pencegahan dan pemulihan dalam isu-isu sosial serta pembangunan masyarakat.

Dengan keterlibatan Jabatan Kebajikan Masyarakat negeri Kedah (JKMK), masalah ini untuk menuntaskan para gelandangan, Jabatan Kebajikan Masyarakat Kedah melakukan berbagai usaha dengan berbagai Non-Government Organization (NGO) untuk sama-sama membantu gelandangan, dan diletakkan di bawah Urusan Dakwah sebagai menjalankan Dakwah Bil Hal, adalah bertujuan untuk terus menyantuni dan menghormati semua gelandangan dengan penerapan nilai-nilai keagamaan (Jabatan Kebajikan Masyarakat Malaysia, 2016)

\section{Metode Penelitian}

Penelitian kualitatif dapat diartikan sebagai metode penelitian yang berlandaskan pada filsafat positivisme yang digunakan untuk meneliti pada kondisi objek yang alamiah, (sebagai lawannya adalah eksperimen) di mana peneliti sebagai instrument kunci, pengambilan sampel sumber data dilakukan secara purposive dan snowball, teknik pengumpulan dengan triangulasi (gabungan), analisa data bersifat induktif/kualitatif dan hasil penelitian lebih menekankan makna daripada generalisasi (Dewi Sadiah, 2015).

Pelaksanaan penelitian ini dilakukan secara alamiah dan turun ke lapangan menyaksikan sendiri situasi tersebut, apa adanya, dalam situasi yang normal sesuai 
dengan keadaan dan kondisinya, menekankan deskripsi secara alami. Dari objek data yang dianalisis, penelitian ini termasuk penelitian deskriptif analisis, yaitu penelitian yang dilakukan dengan langkah-langkah: melakukan analisis terhadap objek tentang keadaan fenomena sosial yang terdapat pada permasalahan yang diteliti kemudian dikaitkan dengan teori yang ada.

\section{Hasil}

Hasil ini adalah hasil penelitian yang dilakukan di Jabatan Kebajikan Masyarakat Negeri Kedah Darul Aman. Penelitian ini dilakukan untuk mendapatkan data tentang bimbingan konseling islam dalam menanggulangi gelandangan di kota Alor Setar oleh Jabatan Kebajikan Masyarakat Negeri Kedah Darul Aman.

Adapun teknik yang penulis gunakan dalam penelitian ini adalah teknik wawancara dan observasi. Wawancara yang penulis lakukan dengan cara mengajukan beberapa pertanyaan kepada informan. Observasi dilakukan dengan mengamati secara langsung di Pejabat Jabatan kebajikan Masyarakat Negeri Kedah bersama Ibuk Solleha Nur Binti Abdul Rahman, Penolong Pengarah Kanan Bahagian Konseling dan Psikologi. Penelitian yang telah dilaksanakan ini penulis sajikan dalam bentuk kata-kata.

Data yang diperoleh dari hasil observasi dan wawancara bersama Ibuk Solleha Nur mengenai Bimbingan Konseling Islam Dalam Menanggulangi Gelandangan Di Kota Alor Setar Oleh Jabatan Kebajikan Masyarakat adalah kerjasama Pemerintah Negeri Kedah dan Jabatan Kebajikan Masyarakat Negeri Kedah menyediakan beberapa Rumah Transit Negara sebagai tempat penampungan sementar bagi mereka yang membutuhkan.

Mereka yang mempunyai masalah boleh memohon melalui Jabatan Kebajikan Masyarakat untuk berlindung di rumah ini, namun mereka akan dinilai terlebih dahulu sebelum dapat tinggal di Rumah Transit Negara. Dalam permasalahan gelandangan, terlebih dahulu pegawai dari bahgian perundangan dan penguatkuasaan di bawah Jabatan Kebajikan Masyarakat akan melakukan operasi untuk menangkap gelandangan di sekitar Kota Alor Setar dan dibawa ke Rumah Transit Negara untuk perlindungan sementara sebelum kasus direkemendasi kepada pegawai psikologi yaitu konselor. Setelah kasus di rekemendasi kepada konselor, bermulalah proses bimbingan konseling islam terhadap gelandangan.

Sejarah pertumbuhan perkotaan banyak ditopang oleh komunitas urban yang menjadi penyangga kehidupan warga kota. Dalam proses interaksi yang terus berlangsung di tempat yang baru, warga dari pedesaan banyak yang kalah dan terpinggirkan dan akhirnya kembali menjadi warga miskin dan marginal di wilayah perkotaan. Menurut Ibuk Solleha Nur, peluang kerja baru mensyaratkan adanya pendidikan, keterampilan dan pengalaman yang memadai sehingga individu tidak mahu berkompetisi dalam mencari peluang pekerjaan.

Selain itu, faktor kelurga yang berantakan, hubungan kekeluargaan yang terputus juga menyebabkan seseorang individu itu memilih untuk membawa diri kepada kehidupan gelandangan seperti dari hasil observasi dan wawancara penulis dengan Bapak Muhammad (bukan nama asli) dan adiknya Nur (bukan nama asli) adalah anak yatim piatu yang kabur dari panti asuhan untuk mencari saudara mereka yang berada di Kota Alor Setar untuk menumpang kasih. Setelah berjumpa keluarga, mereka tidak di terima oleh keluarga dikarenakan masalah ekonomis yang di alami keluarga itu, dan harus menanggung beberapa ahli keluarga lain. 
Telah diuraikan pada BAB II bahwa konseling islam adalah Hakekat bimbingan dan konseling Islami adalah upaya membantu individu belajar mengembangkan fitrahiman dan atau kembali kepada fitrah-iman, dengan cara memberdayakan (enpowering) fitrah-fitrah (jasmani, rohani, nafs, dan iman) mempelajari dan melaksanakan tuntunan Allah dan rasul- Nya, agar fitrah-fitrah yang ada pada individu berkembang dan berfungsi dengan baik dan benar. Pada akhirnya diharapkan agar individu selamat dan memperoleh kebahagiaan yang sejati di dunia dan akhirat.

\section{Pembahasan}

Proses konseling islam terhadap gelandangan di Jabatan Kebajikan Masyarakat Negeri Kedah Darul Aman dilaksanakan secara individu dan kelompok. Konseling ini dilaksanakan mengikut kasus yang dilaporkan kepada Jabatan Kebajikan Masyarakat Negeri Kedah Darul Aman. Dari smber data observasi penulis mengamati bahwa kasus gelandangan ini di ambil alih oleh bahagian lain yaitu bahagian perundangan dan penguatkuasaaan dibawah akta orang papa 1977.

Jabatan Kebajikan Masyarakat memberi fokus kepada golongan yang tiada tempat tinggal dan memerlukan perlindungan yang boleh didefinisikan sebagai orang papa di bawah Akta Orang Papa 1977. Jabatan Kebajikan Masyarakat secara berkala dan ad-hoc sentiasa melakukan operasi bagi menyelamat orang papa yang terdiri daripada pengemis dan kutu rayau(gelandangan).

Setelah di observasi, penulis mendapati bahwa, Orang papa didefinisikan iyaitu Seseorang yang ditemukan sedang mengemis di tempat umum sedemikian rupa sehingga menyebabkan atau dapat menyebabkan kesusahan bagi mereka yang sering mengunjungi tempat itu atau diganggu atau seorang turis ditemukan di tempat umum apakah dia tidak memiliki uang atau tidak mempunyai identitas atau tempat tinggalnya atau yang tidak dapat mengekspresikan dirinya dengan memuaskan.

Menurut analisis penulis bahwa dalam konseling islam di Jabatan Kebajikan Masyarakat Negeri Kedah Darul Aman menyediakan ruangan khusus konseling yang sangat nyaman bersesuaian aturan konseling maka pelaksanaan konseling di jabatan kebajikan masyarakat negeri kedah berjalan dengan efektif.

Proses bimbingan konseling islam terhadap gelandangan di Jabatan Kebajikan Masyarakat Negeri Kedah merupakan sesuatu layanan yang diberikan oleh konselor kepada individu (gelandangan) untuk menyelesaikan permasalahan yang dialami oleh gelandangan dengan pendekatan islami yaitu bertujuan agar gelandangan mendapat kesedaran diri, teguh keimanannya, khususnya kesehatan jiwa dan mental, dapat mengendalikan diri, dan memahami apa yang diperintahkan dan dilarang oleh Allah SWT sehingga apabila gelandangan dapat mandiri menguruskan diri dan hidup.

Ditambah oleh konselor pada wawancara bapak Mohd Hazizi Bin Ishak menyata bahwa: "Setiap individu perlu mempunyai kesadaran dan nilai kemanusiaan terhadap norma kehidupan sosial yang lebih matang agar masalah gelandangan dapat dikurangkan seterusnya dihapuskan dalam membentuk sebuah kehidupan yang lebih harmonis dan sejahtera."

Adapun mengenai metode yang digunakan dalam bimbingan konseling islam ini adalah metode langsung dalam proses konseling islam ini sangat tepat dan dapat memberikan masukan secara langsung kepada gelandangan sesuai dengan keahlian konselor. Konselor di Jabatan Kebajikan Masyarakat Negeri Kedah mengunakan beberapa tehnik dalam proses konseling islam di Jabatan Kebajikan Masyarakat Negeri 
Kedah yaitu, yang pertama dengan interview adalah wawancara secara tatap muka, yang kedua group guidance yaitu berdiskusi secara berkelompok dan yang terakhir adalah client centered method yaitu konsep tentang diri yang bepusat pada klien.

\section{Kesimpulan}

Berdasarkan dari hasil penelitian dan pembahasan yang telah dijelaskan dalam bab-bab terdahulu, maka dapatlah di ambil inti dari pembahasan atau kesimpulan dalam penelitian ini yaitu pertama Bimbingan konseling islam dalang menanggulangi gelandangan di Kota Alor Setar oleh Jabatan Kebajikan Masyarakat Negeri Kedah sangat memperhatikan kondisi kejiwaan dalam diri gelandangan dan bimbingan konseling islam di Jabatan Kebajikan Masyarakat Negeri Kedah menggunakan tiga tahapan iyaitu tahap awal, tahap kedua(pertengahan), dan tahap ketiga (akhir), materi bimbingan konseling islam diarahkan pada tema-tema yang telah ditetapkan sehingga gelandangan dapat mengikuti tahap- tahap konseling dengan baik dan mudah sehingga mereka dapat teguhkan keimanannya, secara khususnya kedekatan jiwa dan mental, dapat mengendalikan diri dan memahami apa yang diperintahkan dan dilarang oleh Allah SWT sehingga gelandangan dapat memulakan kehidupan baru diluar sana.

\section{Referensi}

Ahmad, M. (2010). Strategi Kelangsungan Hidup Gelandangan-Pengemis (Gepeng). Jurnal Penelitian, 7(2), 1-16.

Amin, S. M. (2010). Bimbingan dan konseling Islam. Amzah.

Bakran Adz-Dzaky, M. H. (2002). Psikoterapi dan Konseling Islam: Penerapan Metode Sufistik. Yogyakarta Fajar Pustaka Baru.

Dewi Sadiah, D. (2015). Metode Penelitian Dakwah Pendekatan Kualitatif dan Kuantitatif.

Fitri, I. A. (2019). PENANGGULANGAN GELANDANGAN DAN PENGEMIS DI INDONESIA (Analisis Program Desaku Menanti di Kota Malang, Kota Padang dan Jeneponto). Share: Social Work Journal, 9(1), 1-9.

Gudnanto, G. (2015). Peran Bimbingan Dan Konseling Islami Untuk Mencetak Generasi Emas Indonesia. Jurnal Konseling Gusjigang, 1(1).

Jabatan Kebajikan Masyarakat Malaysia. (2016). Info Bahagia.

Miftahuddin, M., Zatrahadi, M. F., Suhaimi, S., \& Darmawati, D. (2019). TAREKAT NAQSABANDIYAH SEBAGAI TERAPI GANGGUAN MENTAL (Studi di Desa Besilam Kabupaten Langkat Sumatera Utara). Sosial Budaya. https://doi.org/10.24014/sb.v15i2.6753

Mohamed, R. (2015). Gelandangan Antara Tret Personaliti dan Religiositi. ITBM.

Muslim, M. (2013). Penanggulangan Pengemis Dan Gelandangan Di Kota Pekanbaru. Jurnal ElRiyasah, 4(1), 24-35.

Nazif Mohd. (2013). Media Dan Hak Asasi.

Nusanto, B. (2017). PROGRAM PENANGANAN GELANDANGAN DAN PENGEMIS DI KABUPATEN JEMBER (HANDLING PROGRAMS OF HOMELESS AND BEGGAR) IN JEMBER DISTRICT. POLITICO, $17(2)$. 
Rohman, A. (2011). Program Penanganan Gelandangan, Pengemis, dan Anak Jalanan Terpadu Melalui Penguatan Ketahanan Ekonomi Keluarga Berorientasi Desa. Kementerian Sosial RI, Jakarta.

Sam Hisam. (2014). "Bimbingan" 16 Pengertian Menurut Para Ahli.

Twikromo, Y. A. (1999). Gelandangan Yogyakarta: suatu kehidupan dalam bingkai tatanan sosial-budaya" resmi". Penerbitan Universitas Atma Jaya Yogyakarta.

Zefianningsih, B. D., Wibhawa, B., \& Rachim, H. A. (2016). Penanggulangan Gelandangan Dan Pengemis Oleh Panti Sosial Bina Karya "Pangudi Luhur" Bekasi. Prosiding Penelitian Dan Pengabdian Kepada Masyarakat, 3(1). 